\title{
Biologia de Podisus nigrispinus predando lagartas de Alabama argillacea em campo ${ }^{(1)}$
}

\author{
José Eudes Moraes de Oliveira ${ }^{(2)}$, Jorge Braz Torres ${ }^{(2)}$, Alberto Fábio Carrano-Moreira(2) \\ e Francisco de Sousa Ramalho(3)
}

\begin{abstract}
Resumo - Este trabalho estudou o desenvolvimento ninfal, a reprodução e a taxa de predação de Podisus nigrispinus (Dallas) alimentados ou não com lagartas de Alabama argillacea (Huebner) em plantas de algodão no campo. Ninfas e adultos do predador foram confinadas em folhas de algodão sem alimentação ou alimentadas com duas lagartas de $70 \pm 10 \mathrm{mg}$ oferecidas em intervalos de 1, 3 e 6 dias. O desenvolvimento ninfal de P. nigrispinus, exceto no terceiro ínstar, aumentou com o intervalo de alimentação. Ninfas sem alimento atingiram o terceiro ínstar com sobrevivência de $16,7 \%$ e $100 \%$ de mortalidade posteriormente. Com alimentação diária e a cada três dias, a sobrevivência de ninfas de P. nigrispinus foi maior que $60 \%$ e superior àquelas com alimentação a cada seis dias. A predação de lagartas por ninfas alimentadas diariamente foi 12,7 e 13,2 lagartas predadas por indivíduos que originaram machos e fêmeas, respectivamente, e de 54,7 lagartas por fêmea na fase adulta. Fêmeas, com alimentação diária, apresentaram maior fecundidade, porém com períodos de pré-oviposição, de reprodução e de longevidade semelhantes entre todos os intervalos de alimentação. O fornecimento diário de duas lagartas excedeu a taxa diária de predação de ninfas e adultos, que foi de 0,7 e 1,1 lagartas por dia, respectivamente. Intervalos de alimentação de três e seis dias afetaram o desenvolvimento e reprodução de $P$. nigrispinus.
\end{abstract}

Termos para indexação: Gossypium hirsutum, ninfas, predador, agentes de controle biológico.

Biology of Podisus nigrispinus preying on Alabama argillacea caterpillars in field

\begin{abstract}
Nymphal development, reproduction and predation rate of Podisus nigrispinus (Dallas) (Heteroptera: Pentatomidae) deprived of prey or preying upon Alabama argillacea (Huebner) (Lepidoptera: Noctuidae) were studied on cotton plants in field. Nymph and adult bugs were isolated by an organdie bag attached on cotton leaf and were deprived of prey or fed with two caterpillars of $70 \pm 10 \mathrm{mg}$ every 1, 3 and 6 days. After the third instar the developmental time was delayed with food intervals. Nymphs deprived of prey reached the third instar with $16.7 \%$ survivorship, but $100 \%$ died at this stage. Nymphs feeding either daily or every three days showed survivorship superior to $60 \%$ and higher than those fed every six days. Predation of A. argillacea available daily was 12.7 and 13.2 caterpillars per nymphs when originated males and females, respectively. Additionally, females of $P$. nigrispinus preyed in mean 54.7 caterpillars. Females fed daily showed higher fecundity but pre-oviposition, reproductive and longevity periods were similar to the other feeding intervals. The dairy predation rate for nymphs and adults was 0.7 and 1.1 caterpillars per day; thus the availability of two caterpillars per day was in excess. The nymphal development and reproduction of $P$. nigrispinus were affected by food availability at three and six day's intervals.
\end{abstract}

Index terms: Gossypium hirsutum, nymphs, predator, biological control organisms.

\footnotetext{
(1) Aceito para publicação em 18 de abril de 2001. Extraído da Dissertação de Mestrado apresentada pelo primeiro autor à Universidade Federal Rural de Pernambuco (UFRPE), Recife, PE. Parcialmente financiada pela Capes.

(2)UFRPE, Dep. de Agronomia e Fitossanidade, Av. Dom Manoel de Medeiros s/n, Dois Irmãos, CEP 52171-900 Recife, PE. E-mail: jorge@mail.ufrpe.br

${ }^{(3)}$ Embrapa-Centro Nacional de Pesquisa de Algodão, Caixa Postal 174, CEP 58107-720 Campina Grande, PB. E-mail: framalho@cnpa.embrapa.br
}

\section{Introdução}

O curuquerê-do-algodoeiro, Alabama argillacea (Huebner), é considerado uma das principais pragas do algodoeiro, em face da rapidez com que desfolha essa cultura. Sua ocorrência se dá praticamente em todos os locais onde se planta algodão, e sua população varia com as condições climáticas e a idade da planta (Parra et al., 1984). Paralelamente, a cultura 
do algodão também tem sido apontada como um excelente habitat para percevejos predadores, como os pertencentes ao gênero Podisus, os quais possuem potencial para serem usados no controle dessa praga (Gravena \& Cunha, 1991; Santos et al., 1995).

Os predadores são considerados, entre os inimigos naturais, a primeira linha de defesa das plantas contra fitófagos (Whitcomb, 1981); normalmente estão presentes em baixas populações nos agroecossistemas, sendo dependentes da abundância e da qualidade da presa. No caso de Podisus spp., existem relatos de que as populações do predador estão associadas ao final do surto de lagartas desfolhadoras de soja (Corrêa-Ferreira \& Moscardi, 1995) e de eucalipto (Torres et al., 1996a). Embora sejam mais comuns em condições de abundância de alimento, a escassez de presas é uma situação que pode ocorrer imprevisivelmente, proveniente de baixas populações em fase de colonização, decorrente da aplicação de inseticidas ou da ação de outros agentes de controle biológico natural ou aplicado. Assim, para a utilização de Podisus spp. em programas de controle do curuquerê-do-algodoeiro, estudos devem ser voltados à avaliação de seu potencial tanto em condições de abundância como de escassez desta presa, em condições naturais.

O potencial de predação de ninfas e adultos de P. nigrispinus sobre lagartas de terceiro e quarto ínstar de Tuta absoluta (Meyrick) foi avaliado por Vivan (1999). Esse autor reporta semelhança na taxa de predação entre laboratório e telado com a presa na presença da planta. No entanto, Salas (1996) mostrou que para essa mesma presa, o número de lagartas predadas aumenta substancialmente em placas de Petri. Santos et al. (1995) observaram que esse predador no quinto ínstar é capaz de consumir de 9 a 15,8 lagartas de A. argillacea, dependendo da sua idade, em laboratório. De Clercq \& Degheele (1994) encontraram ninfas de quinto ínstar de P. nigrispinus predando de 12 a 40 lagartas de Spodoptera exigua (Hübner), dependendo de sua idade. Portanto, o potencial de predação de P. nigrispinus em diversas presas é dependente do tamanho da presa e pode variar em razão das condições do estudo.

O objetivo deste trabalho foi estudar o desenvolvimento ninfal, a reprodução e a taxa de predação de Podisus nigrispinus alimentados ou não com lagar- tas de Alabama argillacea em plantas de algodão, no campo.

\section{Material e Métodos}

O experimento foi conduzido no campo do Departamento de Agronomia-Fitossanidade da Universidade Federal Rural de Pernambuco (UFRPE), Recife, PE, sob temperatura de $25,8 \pm 4,8^{\circ} \mathrm{C}, 78,1 \pm 20,1 \%$ de U.R. e $75,9 \pm 37,5 \mathrm{~mm}$ de precipitação pluvial (dados fornecidos pela Secretaria de Recursos Hídricos do Estado de Pernambuco).

Plantas de algodão (Gossypium hirsutum L. raça latifolium Hutch), cultivar CNPA Precoce 1, foram cultivadas em campo, com densidade de 50.000 plantas/ha com plantios intercalados a cada 30 dias, para se obterem plantas com folhas adequadas e suficientes para a criação de A. argillacea, em laboratório, e de plantas na fase fenológica para o experimento. Foram feitas capinas e irrigações sempre que necessário. A incidência de pragas foi controlada mecanicamente, exceto na ocorrência do ácaro-vermelho (Tetranychus ludeni Zacker) e do ácarorajado (Tetranychus urticae Koch), quando se utilizou enxofre (Thiovit $600 \mathrm{PM}$ ) na dosagem de $3 \mathrm{~kg} / \mathrm{ha}$, aplicado nas parcelas que não seriam utilizadas no experimento naquele momento. $\mathrm{O}$ experimento foi iniciado com plantas de algodão no estágio de florescimento e com altura variando entre 0,5 e $1,0 \mathrm{~m}$.

As ninfas de P. nigrispinus utilizadas foram criadas e mantidas no laboratório de Controle Biológico de Insetos (UFRPE), de acordo com os métodos propostos por Torres et al. (1996b), a $28 \pm 1{ }^{\circ} \mathrm{C}, 53 \pm 5 \%$ de U.R. e fotoperíodo de 12:12 (luz:escuro), alimentadas com larvas e pupas de Tenebrio molitor L. (Coleoptera: Tenebrionidae).

A criação de A. argillacea foi iniciada a partir de pupas cedidas pela Unidade de Controle Biológico da EmbrapaCentro Nacional de Pesquisa de Algodão, Campina Grande, PB, e mantidas no laboratório nas mesmas condições do predador. Foram colocados cinco casais desse inseto, por gaiola de $\mathrm{PVC}$ medindo $21,5 \mathrm{~cm}$ de altura e $14,5 \mathrm{~cm}$ de diâmetro, forradas com papel sulfite branco, como substrato para oviposição. A parte superior da gaiola foi fechada e sua base apoiada sobre um prato de plástico forrado com papel-filtro. Os adultos de $A$. argillacea foram alimentados com solução de mel (30\%), embebida em esponjas de $0,5 \mathrm{~cm}$ de espessura mantidas no interior da gaiola. A água foi fornecida através de um tubo de vidro de $10 \mathrm{~mL}$ vedado com chumaço de algodão. Durante o período de oviposição, o papel e a organza contendo posturas eram transferidos diariamente para gaiolas semelhantes 
àquelas usadas para adultos. Após dois dias, esses materiais contendo ovos foram depositados sobre as folhas de algodão, as quais foram acondicionadas com seu pecíolo inserido em vidros com água e presos com chumaço de algodão. As pupas de $A$. argillacea, após serem sexadas, foram transferidas para placas de Petri $(9 \mathrm{~cm}$ x 1,5 cm), e após seis dias, acondicionadas nas gaiolas, até a emergência e coleta de posturas.

O experimento foi iniciado com ninfas de $P$. nigrispinus de segundo ínstar ( $<12$ horas), da $21^{a}$ geração, em laboratório. As ninfas foram individualizadas, em gaiolas, presas em folha de algodoeiro e submetidas aos tratamentos (repetições): sem alimentação (30 ninfas), com alimentação diária (40 ninfas), com alimentação a cada três dias (48 ninfas) e a cada seis dias (55 ninfas). Foram disponibilizadas duas lagartas de A. argillacea de 1,5 a 2,0 $\mathrm{cm}$ de comprimento, pesando $70 \pm 10 \mathrm{mg}$ em cada tratamento. Nos tratamentos com intervalos de alimentação, após 24 horas da oferta, as lagartas foram retiradas, mesmo que não tivessem sido predadas, com o objetivo de se evitar alimentação fora do intervalo previsto.

Após atingirem a fase adulta, as fêmeas de $P$. nigrispinus foram mantidas isoladas por três dias para maturação sexual e, posteriormente, acasaladas, mantendo-se os machos até a constatação da cópula, ou durante três dias. Nesse período, o número de lagartas foi duplicado em todos os tratamentos, para se manter a taxa de duas lagartas por predador.

Foram determinados a duração da fase ninfal, o peso de ninfas no início do quinto ínstar e de adultos, a taxa de predação diária da fase ninfal e por ínstar, longevidade de fêmeas, períodos de pré-oviposição e reprodução, número total de ovos por fêmea, número de posturas por fêmea, ovos por postura, taxa diária de produção de ovos e ninfas, de acordo com o período reprodutivo e porcentagem de parasitismo de ovos. Esses resultados foram submetidos a ANOVA simples pelo procedimento do Statistica 3.0 (StatSoft, 1993), sendo os dados das características reprodutivas transformados em $(\mathrm{x}+0,5)^{0,5}$. As médias foram comparadas pelo teste de Tukey HSD (Spjotvoll/ Stoline), em relação aos diferentes tamanhos de amostras, a $5 \%$ de probabilidade. As médias da duração da fase, taxa de predação total e diária foram comparadas pelo teste $\mathrm{t}$ a $5 \%$ de probabilidade, entre sexo, no tratamento com disponibilidade diária de presa.

\section{Resultados e Discussão}

A escassez total de alimento prolongou significativamente a duração do segundo ínstar de P. nigrispinus (Tabela 1). Além disso, a duração do quarto e do quinto ínstar aumentou em ninfas alimentadas a cada seis dias. Isto foi verificado também para a duração do segundo ínstar a adulto, em ninfas que originaram machos ou fêmeas entre os intervalos de alimentação. Fêmeas e machos apresentaram duração semelhante da fase ninfal, quando receberam alimento diariamente ou a cada três dias. Além disso, a disponibilidade diária de alimento proporcionou maior peso de machos e fêmeas (Tabela 1).

Ninfas com escassez total de alimento apresentaram sobrevivência de $16,7 \%$ até atingirem o terceiro ínstar, quando ocorreu $100 \%$ de mortalidade (Figura 1). Do segundo ao quinto ínstar, a sobrevivência de ninfas nos diferentes intervalos de alimentação foi acima de $65 \%$, sendo maior no tratamento com disponibilidade diária de alimento.

A predação diária de ninfas de $P$. nigrispinus com duas lagartas por dia foi maior no segundo, terceiro e quinto ínstar, sendo menor neste último, quando o predador teve presa disponível a cada seis dias (Tabela 2). Do segundo ao quinto ínstar, ninfas que originaram machos ou fêmeas e com disponibilidade diária de presa predaram maior número de lagartas que aquelas alimentadas a cada três e seis dias. Ninfas que originaram fêmeas ou machos e que receberam presa diariamente apresentaram número semelhante de lagartas predadas durante a fase ninfal, e por dia (Tabela 2).

O número de lagartas de $A$. argillacea predadas por fêmea de $P$. nigrispinus foi de 43,0 $0 \pm 11,7$ lagartas, com média diária de $1,11 \pm 0,18$ lagartas. Essa taxa decresceu com a idade da fêmea $(\mathrm{P}<0,001)$ (Figura 2). Ninfas de $P$. nigrispinus que originaram fême-

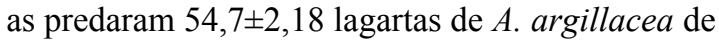
$70 \pm 10 \mathrm{mg}$ durante a fase ninfal.

A longevidade, número de posturas por fêmea, número de ninfas produzidas e período reprodutivo foram semelhantes entre tratamentos (Tabela 3 ). No entanto, o período de pré-oviposição foi maior em fêmeas alimentadas a cada seis dias. Fêmeas com disponibilidade diária de alimento apresentaram maior número total de ovos, de ovos por postura, além de maior taxa diária de oviposição por fêmea e de ninfas por fêmea por dia.

Podisus nigrispinus apresentou desenvolvimento semelhante nos intervalos de alimentação diária e a 
Tabela 1. Duração dos ínstares, duração da fase ninfal e peso de adultos de Podisus nigrispinus (Dallas) (Heteroptera: Pentatomidae) submetidos ao jejum e a diferentes intervalos de alimentação com Alabama argillacea (Huebner) (Lepidoptera: Noctuidae) confinados em plantas de algodão no campo. Recife, PE, $1999^{(1)}$.

\begin{tabular}{|c|c|c|c|c|}
\hline \multirow[t]{2}{*}{ Desenvolvimento ninfal } & \multicolumn{3}{|c|}{ Intervalo de alimentação (dias) } & \multirow[t]{2}{*}{ Sem alimentação } \\
\hline & 1 & 3 & 6 & \\
\hline \multicolumn{5}{|l|}{ Duração do ínstar (dias) } \\
\hline $2^{\underline{o}}$ & $\begin{array}{c}4,0 \pm 1,40 \mathrm{~b} \\
(2-10)\end{array}$ & $\begin{array}{c}4,2 \pm 1,97 b \\
(3-7)\end{array}$ & $\begin{array}{c}4,8 \pm 1,85 \mathrm{~b} \\
(5-8)\end{array}$ & $\begin{array}{c}8,5 \pm 3,15 a \\
\quad(4-17)\end{array}$ \\
\hline $3^{\mathrm{o}}$ & $\begin{array}{c}3,6 \pm 2,23 a \\
(2-11)\end{array}$ & $\begin{array}{c}4,7 \pm 2,70 \mathrm{a} \\
(2-14)\end{array}$ & $\begin{array}{c}4,0 \pm 2,39 a \\
(2-14)\end{array}$ & $\begin{array}{c}7,2 \pm 5,80^{(2)} \\
(2-15)\end{array}$ \\
\hline $4^{\underline{0}}$ & $\begin{array}{c}3,4 \pm 1,52 \mathrm{~b} \\
(2-8)\end{array}$ & $\begin{array}{c}4,4 \pm 1,42 b \\
(3-11)\end{array}$ & $\begin{array}{c}7,6 \pm 2,93 a \\
(4-14)\end{array}$ & \\
\hline $5^{\circ}$ & $\begin{array}{c}6,2 \pm 2,44 \mathrm{~b} \\
(2-8)\end{array}$ & $\begin{array}{c}6,3 \pm 2,27 b \\
(3-11)\end{array}$ & $\begin{array}{c}10,7 \pm 7,82 \mathrm{a} \\
(6-11)\end{array}$ & \\
\hline \multicolumn{5}{|l|}{ Duração da fase (dias) } \\
\hline $2^{\circ}$ ínstar - adulto (macho) & $\begin{array}{c}16,0 \pm 2,75 b \\
(13-22)\end{array}$ & $\begin{array}{c}17,8 \pm 1,23 b \\
(16-20)\end{array}$ & $\begin{array}{c}25,2 \pm 2,60 \mathrm{a} \\
(16-27)\end{array}$ & \\
\hline $2^{2}$ ínstar - adulto (fêmea) & $\begin{array}{c}17,8 \pm 4,14 b \\
(13-28)\end{array}$ & $\begin{array}{c}19,4 \pm 3,21 b \\
(16-28)\end{array}$ & $\begin{array}{c}29,1 \pm 5,66 \mathrm{a} \\
(23-41)\end{array}$ & \\
\hline Peso do macho (mg) & $\begin{array}{c}46,0 \pm 7,24 \mathrm{a} \\
(28-55)\end{array}$ & $\begin{array}{c}42,1 \pm 7,20 \mathrm{ab} \\
(32-54)\end{array}$ & $\begin{array}{c}37,3 \pm 8,08 b \\
(28-43)\end{array}$ & \\
\hline Peso da fềmea (mg) & $\begin{array}{c}65,3 \pm 19,9 a \\
(43-114)\end{array}$ & $\begin{array}{c}51,0 \pm 18,06 \mathrm{~b} \\
(25-71)\end{array}$ & $\begin{array}{c}42,0 \pm 8,88 \mathrm{~b} \\
(32-58)\end{array}$ & \\
\hline
\end{tabular}

${ }^{(1)}$ Médias \pm desvio-padrão (intervalo de variação) seguidas de mesma letra na mesma linha não diferem entre si pelo teste de Tukey (P<0,05). ${ }^{(2)}$ Tempo que sobreviveram, não sendo incluído nas análises.

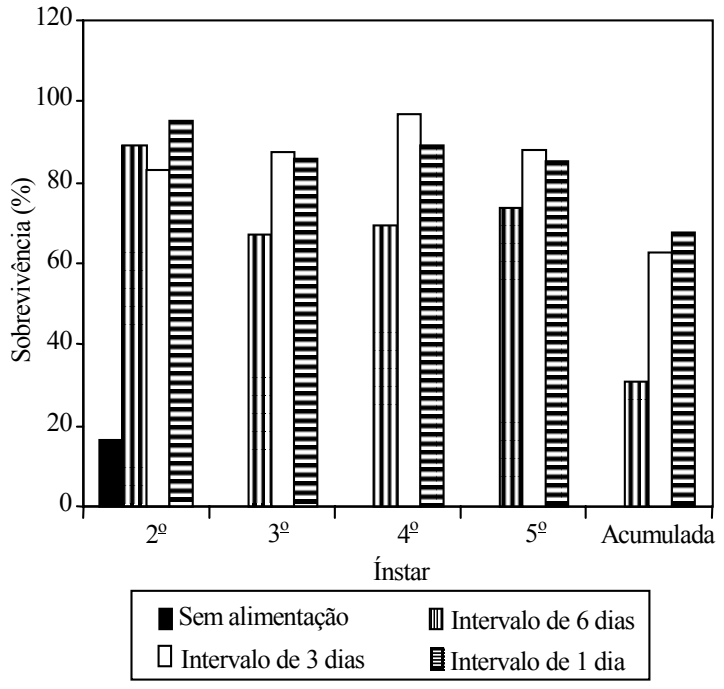

Figura 1. Porcentagem de sobrevivência por ínstar e acumulada do segundo ínstar até a emergência de adultos de Podisus nigrispinus (Dallas) (Heteroptera: Pentatomidae), predando Alabama argillacea (Huebner) (Lepidoptera: Noctuidae), submetidos a diferentes regimes de alimentação, em condições de campo. Recife, PE, 1999. cada três dias, e maior no intervalo de seis dias, o que pode caracterizar situação de escassez de alimento na fase ninfal desse predador. Isso sugere que duas alimentações nos ínstares iniciais (duração ínstar/intervalo de alimentação, Tabela 1) são suficientes para que ninfas de $P$. nigrispinus atinjam a muda. A partir do quarto ínstar, essas ninfas necessitam de maior quantidade de alimento, quando esse predador pode não conseguir alimento suficiente para seu desenvolvimento e originar indivíduos menores em virtude da escassez de presa. Mukerji \& LeRoux (1969) verificaram que Podisus maculiventris (Say) alimentados diariamente com lagartas de aproximadamente $37 \mathrm{mg}$ de Galleria mellonella L. retardaram, significativamente, a duração do quinto ínstar em relação aos anteriores, que foram semelhantes, e dos insetos alimentados com lagartas a partir de $73 \mathrm{mg}$, indicando maior impacto da disponibilidade de alimento nesse ínstar. Isso constata que somente intervalos de alimentação a partir de três dias caracterizam escassez de alimento durante a fase ninfal de $P$. nigrispinus predando lagartas de $70 \pm 10 \mathrm{mg}$ de A. argillacea. 
Tabela 2. Número médio de lagartas de Alabama argillacea (Huebner) (Lepidoptera: Noctuidae) predadas, por ínstar, na fase ninfal por indivíduos que originaram machos e fêmeas, e diariamente por Podisus nigrispinus (Dallas) (Heteroptera: Pentatomidae) submetidos a diferentes intervalos de alimentação em condições de campo. Recife, PE, 1999(1).

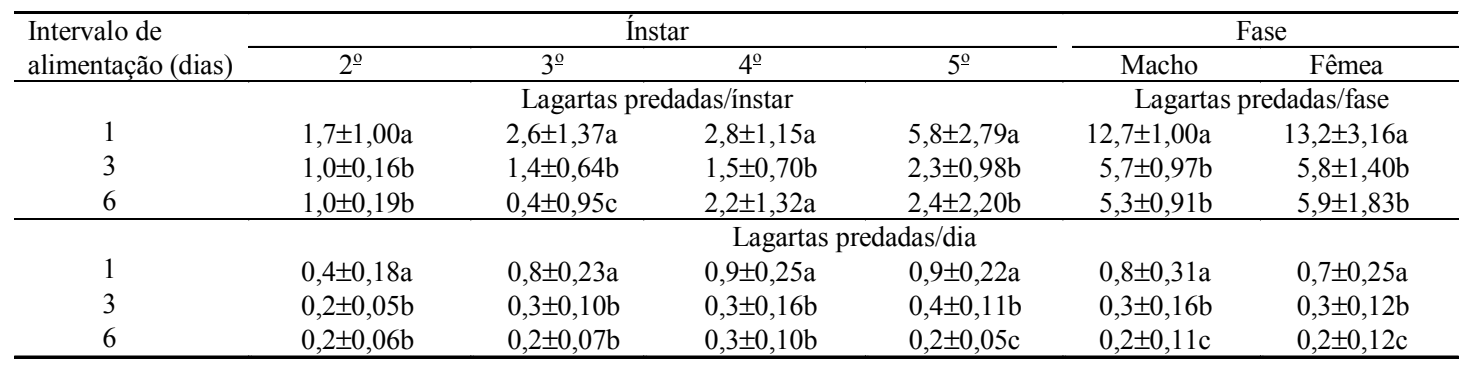

${ }^{(1)}$ Médias \pm desvio-padrão seguidas de mesma letra na coluna não diferem entre si pelo teste de Tukey $(\mathrm{P}<0,05)$.

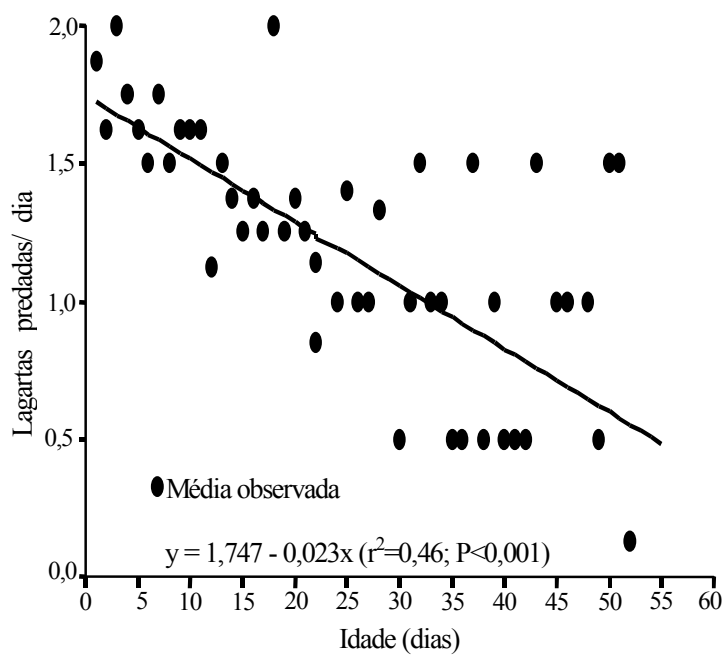

Figura 2. Predação diária de lagartas de Alabama argillacea (Huebner) (Lepidoptera: Noctuidae), de acordo com a idade das fêmeas de Podisus nigrispinus (Dallas) (Heteroptera: Pentatomidae), em plantas de algodão, em condições de campo. Recife, PE, 1999.

Mesmo em situações de disponibilidade diária da presa, esse predador apresentou maior período ninfal (Tabela 1) que o relatado por outros estudos em laboratório. Santos et al. (1995) relataram peso médio de 72,4 $\pm 1,55$ mg e duração de 13,2 dias na fase ninfal desse predador. De Clercq \& Degheele (1994) encontraram período de 18,6 dias com P. nigrispinus, sobre Spodoptera exigua (Hübner) de terceiro ínstar. Tal comportamento sugere que o aumento da duração da fase ninfal deve ser conseqüência das condições de campo. Assim, a duração da fase ninfal de percevejos predadores é variável com a presa e as condições ambientais, que podem prolongar a fase ninfal desses predadores, como verificado neste estudo, o que não chega a ser uma característica indesejável para $P$. nigrispinus.

$\mathrm{O}$ peso de adultos diminuiu com o aumento do intervalo de alimentação (Tabela 1), e mesmo a disponibilidade de presa, a intervalos a partir de três dias, para predadores induz a menor ganho de peso e acúmulo de reservas, podendo comprometer seu sucesso reprodutivo, pois fêmeas mais pesadas apresentam maior fecundidade (Zanuncio et al., 1992). Esse fato justifica os menores pesos de indivíduos provenientes de campo, onde estão submetidos à imprevisibilidade de alimento. Fêmeas aos três dias de idade aumentaram seus pesos em $13 \mathrm{mg}, 7,7 \mathrm{mg}$ e $0,13 \mathrm{mg}$ com disponibilidade diária, e a intervalos a cada três e seis dias de disponibilidade, respectivamente. Tais diferenças são resultantes, principalmente, da ingestão de alimento e formação de estruturas reprodutivas durante a maturação sexual. Menores pesos de fêmeas de $P$. maculiventris de campo foram constatados por Legaspi et al. (1996), sugerindo que predadores mantidos nessas condições não necessariamente apresentarão pesos semelhantes àqueles de laboratório. No entanto, segundo esses autores o ganho de peso é retomado quando os predadores estão em condições adequadas de disponibilidade de presa. Tal fato foi observado com $P$. nigrispinus (Zanuncio et al., 1996), com variações na qualidade da presa durante a fase ninfal e da ingestão de alimento e de freqüência de oviposição desse predador (De Clercq \& Degheele, 1997).

Embora Wiedenmann \& O'Neil (1990) tenham conduzido experimentos com fêmeas virgens de P. maculiventris, para evitar o canibalismo em estu- 
dos de intervalos de alimentação, resultados têm mostrado que o acasalamento afeta, principalmente, a longevidade, a taxa de oviposição, a fertilidade desses predadores, bem como sua taxa de predação (De Clercq \& Degheele, 1997; Torres et al., 1997). Por isso, optou-se por uma cópula aos três dias de idade da fêmea, e manteve-se o acasalamento por três dias. Uma cópula foi insuficiente para a manutenção da fertilidade da fêmea de P. nigrispinus, com alimentação diária, e, conseqüentemente, a produção de ninfas foi semelhante nos diferentes tratamentos (Tabela 1). Fêmeas com alimentação diária produziram aproximadamente o dobro de ovos que aquelas alimentadas a intervalos de três e seis dias, porém revelou semelhança em relação à quantidade de ninfas produzidas. Isso ainda pode ser reforçado pela maior taxa de produção de ninfas em razão do período reprodutivo, nas fêmeas alimentadas diariamente (Tabela 1). O parasitóide de ovos Telenomus podisi Ashmead (Himenoptera: Scelionidae) foi encontrado em ovos de $P$. nigrispinus, em todos os tratamentos, com parasitismo de $7,1 \%$ a $9 \%$, o que pode reduzir a produção de ninfas de $P$. nigrispinus. Esse

Tabela 3. Médias e intervalo de variação (entre parênteses) dos parâmetros reprodutivos de Podisus nigrispinus (Dallas) (Heteroptera: Pentatomidae), predando Alabama argillacea (Huebner) (Lepidoptera: Noctuidae), submetido a diferentes intervalos de alimentação, em condições de campo. Recife, PE, 1999(1).

\begin{tabular}{lccc}
\hline Parâmetro & \multicolumn{3}{c}{ Intervalo de alimentação (dias) } \\
\cline { 2 - 4 } & 1 & 3 & 6 \\
\hline Longevidade de & $31,5 \pm 14,54 \mathrm{a}$ & $36,0 \pm 10,40 \mathrm{a}$ & $39,6 \pm 18,37 \mathrm{a}$ \\
fêmeas (dias) & $(13-55)$ & $(18-50)$ & $(15-71)$ \\
Período de & $5,8 \pm 2,53 \mathrm{a}$ & $7,6 \pm 3,20 \mathrm{ab}$ & $11,2 \pm 5,09 \mathrm{~b}$ \\
pré-oviposição (dias) & $(3-9)$ & $(4-13)$ & $(6-20)$ \\
Período reprodutivo & $17,6 \pm 13,57 \mathrm{a}$ & $20,5 \pm 11,22 \mathrm{a}$ & $23,2 \pm 15,07 \mathrm{a}$ \\
(dias) & $(4-46)$ & $(3-40)$ & $(6-55)$ \\
Número total de & $303,5 \pm 192,94 \mathrm{a}$ & $147,0 \pm 74,19 \mathrm{~b}$ & $105,5 \pm 64,91 \mathrm{~b}$ \\
ovos & $(39-553)$ & $(55-298)$ & $(47-249)$ \\
Número total de & $107,0 \pm 62,05 \mathrm{a}$ & $80,4 \pm 58,97 \mathrm{a}$ & $53,5 \pm 39,70 \mathrm{a}$ \\
ninfas & $(27-209)$ & $(20-195)$ & $(29-145)$ \\
Número de & $26,5 \pm 8,10 \mathrm{a}$ & $15,8 \pm 2,92 \mathrm{~b}$ & $14,0 \pm 1,84 \mathrm{~b}$ \\
ovos/postura & $(4-81)$ & $(3-61)$ & $(2-41)$ \\
Taxa diária de & $9,1 \pm 3,71 \mathrm{a}$ & $4,0 \pm 1,48 \mathrm{~b}$ & $2,6 \pm 0,96 \mathrm{~b}$ \\
oviposição/fềmea & $(3,0-14,7)$ & $(2,1-7,3)$ & $(1,7-4,5)$ \\
Número de & $12,2 \pm 8,36 \mathrm{a}$ & $9,2 \pm 4,08 \mathrm{a}$ & $7,6 \pm 4,68 \mathrm{a}$ \\
posturas/fềmea & $(4-24)$ & $(3-16)$ & $(3-18)$ \\
Produção de & $11,8 \pm 17,95 \mathrm{a}$ & $4,0 \pm 2,06 \mathrm{ab}$ & $2,9 \pm 1,23 \mathrm{~b}$ \\
ninfas/fêmea/dia & $(2,5-56)$ & $(1,6-6,3)$ & $(1,5-4,8)$ \\
\hline
\end{tabular}

${ }^{(1)}$ Médias \pm desvio-padrão seguidas de mesma letra na mesma linha não diferem entre si pelo teste de Tukey $(\mathrm{P}<0,05)$.

Pesq. agropec. bras., Brasília, v. 37, n. 1, p. 7-14, jan. 2002 parasitismo é relatado também com espécies de Podisus em campos de soja (Corrêa-Ferreira \& Moscardi, 1995) e em eucalipto (Torres et al., 1996a), no Brasil, bem como em espécies co-específicas, em outros países (Johnson, 1984).

O número de lagartas de $A$. argillacea predadas aumentou do segundo ao quinto ínstar de P. nigrispinus (Tabela 2). Mesmo comportamento também tem sido verificado em relação a espécies co-específicas submetidas a diferentes tipos de presas e condições climáticas, o que pode caracterizar um padrão quanto a esses predadores (Mukerji \& LeRoux, 1969; De Clercq \& Degheele, 1994; Colazza et al., 1995; Léo, 1997). Ninfas de P. nigrispinus predaram número superior de lagartas de A. argillacea que as relatadas por Santos et al. (1995), os quais encontraram taxa de predação de 8,6 lagartas de $A$. argillacea de terceiro ínstar, em laboratório. Salas (1996) observou que P. nigrispinus apresentou taxa de predação de 138,9 lagartas de T. absoluta em placas de Petri sob condições de laboratório, durante a fase ninfal. Entretanto, Vivan (1999) verificou em plantas de tomate que $P$. nigrispinus nas fases ninfal e adulta predou de 43,1 a 50,8 e 38,2 a 50,3 lagartas de T. absoluta em laboratório e casa telada, respectivamente. A taxa de predação de lagartas de $A$. argillacea no campo por ninfas e adultos de P. nigrispinus pode estar associada à maior susceptibilidade, pelo menor tamanho das presas utilizadas $(70 \pm 10 \mathrm{mg})$ em relação às lagartas maiores (Santos et al., 1995). Além disso, lagartas ao se alimentarem provocam vibrações que favorecem sua localização e, conseqüentemente, estimulam $\mathrm{o}$ ataque do predador (Pfannestiel et al., 1995).

Resultados semelhantes aos obtidos quanto a algumas características reprodutivas de $P$. nigrispinus são relatados por De Clercq \& Degheele (1992). Com cinco intervalos de alimentação de $P$. nigrispinus com Galleria mellonella L., esses autores mostraram que à medida que o grau de escassez de alimento aumenta, o número de ovos/fêmea diminui. Molina-Rugama et al. (1998) obtiveram longevidade semelhante de fêmeas de $P$. nigrispinus em intervalos de até quatro dias e queda brusca nos intervalos seguintes quando alimentadas com larvas de Musca domestica L. sob condições de laboratório. Legaspi \& O’Neil (1993) observaram que fêmeas de P. maculiventris, predando 
Epilachna varivestis (Mulsant), apresentaram período de pré-oviposição, número de ovos por dia e longevidade semelhantes, com alimentação diária e a intervalos de alimentação de até três dias. No entanto, fêmeas de $P$. nigrispinus mantiveram sua longevidade predando $A$. argillacea com intervalos de até seis dias, o que caracteriza o potencial de manutenção deste predador em campo, em situações de baixa população dessa presa.

A disponibilidade diária de duas lagartas de A. argillacea representou abundância de alimento para ninfas e fêmeas de $P$. nigrispinus, que predaram 0,7 lagartas/dia/ninfa e 1,1 lagartas/dia/fêmea. Tais valores estão de acordo com os obtidos para essa espécie com outras presas e espécies, como $P$. maculiventris e $P$. rostralis Stal (O’Neil, 1988; Léo, 1997). A disponibilidade de alimento a intervalos de três dias indicou situação de escassez de presa, afetando o peso de fêmeas e a taxa reprodutiva de $P$. nigrispinus, mas não afetou a sobrevivência de ninfas e a longevidade de adultos desse predador. Este estudo mostrou o potencial de predação de lagartas de terceiro/quarto ínstar de curuquerê-do-algodoeiro por ninfas e adultos de $P$. nigrispinus, e que em condições de campo esse predador pode responder a esta presa de forma semelhante aos resultados obtidos em outros testes de laboratório.

\section{Conclusões}

1. O desenvolvimento e reprodução de Podisus nigrispinus são afetados diferentemente, de acordo com os intervalos de alimentação de um, três e seis dias.

2. Até três dias de intervalo entre alimentações o desenvolvimento ninfal de $P$. nigrispinus não é afetado.

3. A fecundidade de $P$. nigrispinus é o parâmetro mais afetado pelos intervalos de alimentação.

4. Fêmeas de P. nigrispinus mantêm sua longevidade em intervalos de até seis dias de alimentação.

5. Ninfas que originam fêmeas e machos de P. nigrispinus apresentam igual taxa de predação de Alabama argillacea.

6. Fêmeas de $P$. nigrispinus predam em média 43,0 $\pm 11,7$ lagartas de $A$. argillacea com $70 \pm 10 \mathrm{mg}$, e apresentam decréscimo significativo da taxa de predação com a idade.

\section{Agradecimentos}

A Capes, CNPq e Facepe, pela concessão de bolsas de estudo; a Walter Santos Evangelista Júnior, pela manutenção da colônia do predador; a Murilo Rodrigues da Silva, pelo auxílio na criação do curuquerê; à Dra. Marta Loiácono (Museo de La Plata, Argentina), pela identificação do parasitóide de ovos.

\section{Referências}

COLAZZA, S.; CZEPAK, C.; ISIDORO, N. Introduzione di due predatori Americani in Italia, Podisus maculiventris (Say) e P. connexivus Bergroth, per il controllo biologico di fitofagi esotici (Heteroptera: Pentatomidae). Redia, Perugia, v. 78, n. 2, p. 379-388, 1995.

CORRÊA-FERREIRA, B. S.; MOSCARDI, F. Seasonal occurrence and host spectrum of egg parasitoids associated with soybean stink bugs. Biological Control, San Diego, v. 5, p. 196-202, 1995.

DE CLERCQ, P.; DEGHEELE, D. Effects of mating status on body weight, oviposition, egg load, and predation in the predatory stinkbug Podisus maculiventris (Heteroptera: Pentatomidae). Annals of the Entomological Society of America, Lanham, v. 90, n. 1, p. 121-127, 1997.

DE CLERCQ, P.; DEGHEELE, D. Influence of feeding interval on reproduction and longevity of Podisus sagitta (Het.: Pentatomidae). Entomophaga, Paris, v. 37, n. 4, p. 583-590, 1992.

DE CLERCQ, P.; DEGHEELE, D. Laboratory measurement of predation by Podisus maculiventris and P. sagitta (Hemiptera: Pentatomidae) on beet armyworm (Lepidoptera: Noctuidae). Journal of Economic Entomology, Lanham, v. 87, n. 1, p. 76-83, 1994.

GRAVENA, S.; CUNHA, H. F. Predation of cotton leafworm first ínstar larvae, Alabama argillacea (Lep.: Noctuidae). Entomophaga, Paris, v. 6, n. 4, p. 418-491, 1991.

JOHNSON, N. F. Systematic of Neartic Telenomus: classification and revisions of the Podisi and Phymatae species groups (Hymenoptera: Scelionidae). Bulletin of the Ohio Biological Survey, Columbus, v. 6, n. 3, p. 1-113, 1984.

LEGASPI, J. C.; O’NEIL, R. J. Life history of Podisus maculiventris given low numbers of Epilachna varivestis as prey. Environmental Entomology, Lanham, v. 22, n. 5, p.1192-1200, 1993.

LEGASPI, J. C.; O’NEIL, R. J.; LEGASPI, B. C. Tradeoffs in body weights, egg loads, and fat reserves of field- 
collected Podisus maculiventris (Heteroptera: Pentatomidae). Environmental Entomology, Lanham, v. 25, n. 1, p. 155-164, 1996.

LÉO, E. A. Aspectos morfofisiológicos e de predação do percevejo Podisus rostralis (Heteroptera: Pentatomidae) sobre a lagarta de eucalipto Euselasia apisaon (Lepidoptera: Riodinidae). Viçosa, MG: UFV, 1997. 55 p. Dissertação de Mestrado.

MOLINA-RUGAMA, A. J.; ZANUNCIO, J. C.; PRATISSOLI, D.; CRUZ, I. Efeito do intervalo de alimentação na reprodução e na longevidade do predador Podisus nigrispinus (Dallas) (Heteroptera: Pentatomidae). Anais da Sociedade Entomológica do Brasil, Londrina, v. 27, n. 1, p. $77-84,1998$.

MUKERJI, M. K.; LEROUX, E. J. A quantitative study of consumption and growth of Podisus maculiventris (Hemiptera: Pentatomidae). The Canadian Entomologist, Ottawa, v. 101, p. 387-403, 1969.

O’NEIL, R. J. Predation by Podisus maculiventris (Say) on Mexican bean beetle, Epilachna varivestis Mulsant, in Indiana soybeans. Canadian Entomologist, Ottawa, v. 120, p. 161-166, 1988.

PARRA, J. R. P.; SILVEIRA NETO, S.; KASTEN JUNIOR, P.; BRUNINI, O. Bioecologia de Alabama argillacea. II. Evolução populacional em seis regiões do estado de São Paulo, com base em suas exigências térmicas. Pesquisa Agropecuária Brasileira, Brasília, v. 19, n. 4, p. 417-421, abr.1984.

PFANNESTIEL, R. S.; HUNT, R. E.; YEARGAN, K. V. Orientation of a hemipteran predator to vibrations produced by feeding caterpillars. Journal of Insect Behavior, Dordrecht, v. 8, n. 1, p. 1-9, 1995.

SALAS, S. J. M. Manejo integrado de Tuta absoluta (Meyrick, 1917) (Lepidoptera: Gelechiidae) através de inseticidas fisiológicos e Podisus nigrispinus (Dallas, 1851) (Hemiptera: Pentatomidae). Piracicaba: Esalq, 1996. 128 p. Tese de Doutorado.

SANTOS, T. M.; SILVA, E. N.; RAMALHO, F. S. Desenvolvimento ninfal de Podisus connexivus Bergroth (Hemiptera: Pentatomidae) alimentado com curuquerê-doalgodoeiro. Pesquisa Agropecuária Brasileira, Brasília, v. 30, n. 1, p. 163-167, jan.1995.

STATSOFT INC. (Tulsa, Estados Unidos). STATISTICA 3.0. Tulsa, 1993. v. 1.
TORRES, J. B.; ZANUNCIO, J. C.; CECON, P. R.; GASPERAZZO, W. L. Mortalidade de Podisus nigrispinus (Dallas) por parasitóides de ovos em áreas de eucalipto. Anais da Sociedade Entomológica do Brasil, Londrina, v. 25, n. 3 , p. $463-471,1996$ a.

TORRES, J. B.; ZANUNCIO, J. C.; OLIVEIRA, M. C. Mating frequence and its effect on female reproductive output in the stinkbug predator Podisus nigrispinus (Heteroptera: Pentatomidae). Mededelingen Faculteit Landbouwwetenschappen Rijksuniversiteit Gent, Ghent, v. 62, n. 2a, p. 491-498, 1997.

TORRES, J. B.; ZANUNCIO, J. C.; ZANUNCIO, T. V. Produção e uso de percevejos predadores no controle biológico de pragas florestais. In: WORKSHOP SOBRE PROTEÇÃO FLORESTAL DO MERCOSUL, 1., 1996, Santa Maria. Anais... Santa Maria: UFSM-Centro de Pesquisas Florestais, 1996b. p. 41-51.

VIVAN, L. M. Desenvolvimento e reprodução de Podisus nigrispinus (Dallas) (Heteroptera: Pentatomidae) sobre Tuta absoluta (Meyrick) (Lepidoptera: Gelechiidae) e Tenebrio molitor (L.) (Coleoptera: Tenebrionidae) em casa-de-vegetação e laboratório. Recife: UFRPE, 1999. 61 p. Dissertação de Mestrado.

WIEDENMANN, R. N.; O’NEIL, R. J. Effects of low rates of predation on selected life-history characteristics of Podisus maculiventris (Say) (Heteroptera: Pentatomidae). Canadian Entomologist, Ottawa, v. 22, p. 271-283, 1990.

WHITCOMB, W. H. The use of predators in insect control. In: PIMENTEL, D. (Ed.). CRC handbook of pest management in agriculture. Boca Raton: CRC, 1981. p. 105-123.

ZANUNCIO, J. C.; BRAGANÇA, M. A. L.; DIAZ, J. L. S.; SARTÓRIO, R. C. Avaliação dos parâmetros de fecundidade de Podisus connexivus (Hemiptera: Pentatomidae) de diferentes pesos. Revista Ceres, Viçosa, MG, v. 39, n. 394, p. 591-596, 1992.

ZANUNCIO, J. C.; SAAVEDRA, J. L.; ZANUNCIO, T. V.; SANTOS, G. P. Incremento en el peso de ninfas y adultos de Podisus nigrispinus (Heteroptera: Pentatomidae) alimentados con dos tipos de larva. Revista de Biología Tropical, San José, v. 44, n. 1, p. 241-245, 1996. 